\title{
A perversão no território: os efeitos do desmentido*1
}

\author{
Ivo de Andrade Lima Filho*2 \\ Vera Lúcia Dutra Facundes*3
}

Este artigo discute os efeitos do desmentido (Verleugnung) do perverso sobre o outro, a coletividade, destacando seus possiveis endereçamentos. Trata-se de uma pesquisa ação realizada em uma unidade de Saúde da Família em Recife (PE). Os participantes foram agentes comunitárias de saúde em grupos reflexivos. Problematizouse um fragmento clínico em que uma criança era abusada por um perverso. Destacou-se a necessidade de uma intervenção para barrar o gozo do perverso e libertar a criança.

Palavras-chave: Perversão, atenção primária à saúde, psicanálise, saúde mental

*1 Este artigo foi elaborado a partir das ações desenvolvidas no âmbito do projeto de extensão universitária "Ações interdisciplinares na atenção a pessoas em situações de vulnerabilidade social”, aprovado pelo Edital 2012-PROEXT-UFPE-PIBEX-GRANDE RECIFE, e apresentado no Colóquio Internacional sobre Metapsicologia da Perversão. Usos Sociais da Perversão, em 27/08/2013, na Universidade Católica de Pernambuco, em Recife (PE).

*2 Universidade Federal de Pernambuco - UFPE (Recife, PE, Br.).

${ }^{* 3}$ Universidade Federal de Pernambuco - UFPE (Recife, PE, Br.). 
Este artigo tem por objetivo desenvolver algumas ideias acerca dos efeitos do desmentido (Verleugnung) do perverso sobre o outro, a coletividade, destacando seus possíveis endereçamentos. Destacaremos um fragmento da experiência clínica desenvolvida em uma unidade de Saúde da Família em Recife (PE), com participação das agentes comunitárias de saúde, e relacionaremos esse fragmento clínico ao tema perversão e os efeitos do desmentido no coletivo.

As contribuições acerca das mutações do laço social desenvolvidas por Lebrun (2008, p. 46) constituem um pano de fundo para as reflexões. Para o autor, o laço social entre sujeitos não inclui mais a negatividade, ou seja, não inclui um Outro como terceiro que funcione como lugar de exceção, o lugar da falta. Isso tem sérias consequências para o próprio laço social, caracterizando-se por um "entodamento" do coletivo diante de uma economia perversa que orientaria o singular. Estamos vivenciando um grande desafio, que é apontar os mal-estares contemporâneos decorrentes das mutações no laço social e, ao mesmo tempo, apontar os movimentos no social de resistência e de construções de possibilidades tecidas no interior das novas configurações do social. Nesse sentido, tentaremos contribuir com esses sinais de resistência que nascem no interior desse social em mutação.

\section{Intervenções no território}

O interesse em desenvolver ações na atenção primária à saúde, mais especificamente em uma unidade de Saúde da Família, teve início em 2011, por meio do trabalho de extensão universitária realizado por professores do Departamento de Terapia Ocupacional da Universidade Federal de Pernambuco (UFPE). A seguir, descreveremos um fragmento clínico apresentado e discutido com as agentes comunitárias de saúde em grupos reflexivos instituídos para falar das situações difíceis enfrentadas na comunidade. 


\section{Uma situação perversa}

Trata-se de uma família composta de mãe, padrasto, três filhas e um filho. A mãe é usuária de drogas (crack). O companheiro da mãe e padrasto das crianças é ligado à criminalidade e tem passagens por presídios. Com frequência, a mãe utiliza os filhos como intermediários para obter drogas. Há relatos de que, quando a mãe sai de casa para adquiri-las, o padrasto aproveita para abusar sexualmente da enteada de 12 anos. A mãe é conivente com a situação de abuso da própria filha, pois não deseja perder seu companheiro. Essa situação impedia a menina de brincar na rua e ir à escola. Em sua rua, todos sabem; inclusive uma vizinha que é do Conselho Tutelar. Entretanto, ninguém denuncia por medo de represália do padrasto, que é extremamente violento.

A agente comunitária de saúde (ACS) relatou que há outras histórias de abuso sexual de crianças nessa família. Primos dessa menina de 12 anos costumam assistir filmes pornográficos e ver os pais "fazendo sexo". Os pais justificam que isso serve para que elas, crianças, aprendam desde cedo.

A apresentação desse caso é acompanhada por inúmeras situações em que se associam violência infantil, criminalidade e transtornos mentais. Entretanto, uma coisa chamou a atenção: o estado de paralisia e desânimo dos ACS, embora fosse visível que estavam bastante preocupados com essas situações. Durante alguns encontros, o grupo permanecia sentindo-se impotente diante dos diferentes casos já conhecidos de todos e sem solução. Uma ACS diz sentir-se frustrada diante da impotência diante dos casos na comunidade e complementa: "Principalmente porque não podemos contar com a ajuda do Conselho Tutelar". Há um sentimento de que não há a quem recorrer. A lei mostra-se falha, frágil, e o grupo tem uma sensação de desamparo. Além da impressão de que a lei, representada pelo Conselho Tutelar, é inoperante, o grupo utiliza a palavra "fingimento" para descrever o modus operandi ao lidar com insucessos há muito conhecidos. A palavra "fingimento" surge com um grito de raiva de uma ACS após vários encontros em que foram relatados os casos difíceis da comunidade. E ela "grita": "Nós, ACS, junto com a equipe do NASF [Núcleo de Apoio à Saúde da Família] funcionamos da seguinte forma: eles fingem que fazem, nós fingimos que está sendo feito e, no final, todos fingem que o caso foi solucionado". Tal palavra, de imediato, nos remeteu à palavra alemã Verleugnung, traduzida em português por desmentido e trabalhada por Freud quando discutiu o mecanismo de defesa do perverso. O desmentido é uma negação da realidade perceptível, da castração simbólica. Embora identificada à negação na perversão, Verleugnung é um mecanismo de defesa arcaico que se encontra nas demais estruturas clínicas, como afirma Queiroz (2004), e tem seus efeitos observados na forma de enunciar o discurso do perverso. Um discurso com efeitos de mostração: o 


\section{ARTIGOS}

perverso mostra com palavras, e com o corpo, a desmensura do humano, pois, aí, a lei da castração falhou. Ainda segundo a autora, comentando o ensinamento de Serge André, o perverso se mantém identificado a um pai pré-histórico, ao pai da horda, colocando-se, portanto, como algo fora da regra.

Ora, isso permite pensar que no caso da perversão, não há sujeitos, e sim assujeitados, pois, da mesma forma que suas vítimas, o perverso também se coloca como assujeitado à versão do pai primevo, e não à versão de uma lei consensualmente aceita. (Queiroz, 2004, p. 107)

Nossa hipótese é a de que o padrasto da menina de 12 anos, ocupando na comunidade o lugar de tudo poder, isto é, do pai perverso, do pai pré-histórico, assujeitava a menina, e ao mesmo tempo todos, por meio de seu modo de gozar, e isso tinha suas consequências. Uma ACS denuncia o "fingimento", que se instala em todos devido à força do imperativo de gozo de UM. De UM pai que tudo pode.

A partir da denúncia do "fingimento", o grupo começou a pensar em alternativas para sair da situação de paralisia e impotência diante dos fatos de violência infantil que envolvia, inclusive, o uso de drogas. Essa situação mobilizou o grupo a pensar sobre a sexualidade no mundo contemporâneo, os efeitos da mídia, das novelas, sobre os valores das famílias e da importância da educação sexual nas escolas. Por alguns momentos, sentimos que se falava sobre a perversão no social, a saber, sobre os pactos com os quais se goza do outro. Nessas conversas, uma ACS lembrou que a menina tinha uma avó que parecia uma senhora preocupada com a família e decidiu procurá-la para conversar sobre o abuso sofrido pela neta. A conversa com a avó surtiu efeitos para o grupo e para a menina. No encontro seguinte, a ACS relatou que a avó foi morar em um quarto no fundo da casa, quarto este onde a neta sofria abuso. A partir dessa mudança de posição e lugar da avó, ocupando na casa e para a menina uma posição estratégica, lugar da lei, foi possível vê-la novamente na rua brincando e retornando à escola. A mãe da menina e a avó a levaram à unidade de saúde para dar início a uma longa e, quem sabe, nova história.

\section{Efeitos/endereçamentos do desmentido}

Quais efeitos teria desencadeado na menina, no grupo das agentes comunitárias e na própria comunidade o fato de o padrasto perverso ter sido barrado em seu gozo, não por um representante legal, institucional, mas por uma avó convocada por um outro semelhante (agente comunitária)? Em qual medida o desmentido, como mecanismo de negação originária da realidade perceptível, contribuiu para a instalação do "fingimento" descrito pela agente comunitária? Tais questões 
possibilitaram refletir sobre os efeitos do desmentido e seus possíveis endereçamentos sobre o outro e a coletividade. E é sobre isso que falaremos agora.

Partiremos de uma hipótese que estaria na base ou na lógica do funcionamento do desmentido no novo laço social, a saber: o Outro (simbólico) é permeável, poroso em relação às mutações dos laços sociais. E a porosidade do simbólico favorece o trabalho e destaque da Verleugnung no enlaçamento de cada um ao semelhante-outro e ao Outro. Tal trabalho do desmentido tem se realçado não porque há um déficit ou uma falência na função paterna, mas, antes, a função paterna tornou-se complexa e foi alterada. Dentre tantas questões que se possa pensar na complexidade que envolve a função paterna na contemporaneidade, destaca-se uma que nos parece emblemática: a relação entre a função paterna e a experiência da virtualidade, ou melhor, do virtual como registro que tem contribuído para as novas configurações subjetivas. Lebrun (2004) ao refletir sobre o simbólico virtual cita Pierre Lévy, que afirma que o virtual não se opõe ao real, mas, sim, ao atual. A virtualidade e atualidade são duas maneiras de ser diferentes. Nesse sentido, o virtual só existe em potência, como força, e não como ato. Se o virtual existe enquanto potência, à semelhança da árvore que está virtualmente presente na semente, como lembra o autor, a função paterna, mesmo que se mostre muitas vezes falha em sua dimensão de ato, não significa estar ausente como potência e força na cultura. Parece que ela, a função paterna, inscreve-se na cultura contemporânea de forma paradoxal: nas dimensões virtual e atual em um simbólico poroso afetado por diferentes discursos em rede.

Com o advento da era tecnológica e da ciência, o registro do virtual vem seduzindo e/ou convocando todos a estar em uma rede discursiva horizontal, onde tudo pode ser veiculado, mostrado. Castells (1999, citado por Mittman, 2011, p. 120) denomina sociedade em rede "uma sociedade em que tudo está articulado de forma transversal e onde há menos controle das instituições tradicionais", onde rede é compreendida como "um conjunto de nós interconectados" e o que o nó é depende do tipo de redes concretas de que falamos. O saber é deslocado para a rede e o pai da tradição, como função terceira, perde sua hegemonia e força. Mesmo sem negar que essa característica cria uma série de mal-estares no contemporâneo, não devemos nos apressar em conclusões negativistas sobre o tempo em que vivemos, mas, antes, apontar o paradoxo em que nos encontramos: originalmente filhos da tradição de UM pai e contemporaneamente de um pai tecido em rede e que pode se tornar original. A saber, de um lado, parece que, enquanto função, o pai se enfraquece como ato; de outro lado, é potência enquanto virtualidade.

A noção de rede tem sido bastante discutida na cultura. Frequentemente, utilizamos as expressões rede de saúde mental, discursos em rede e sociedade em rede, como afirma Castells (1999). Essas expressões apontam um sistema descentrado e horizontal, que tem outra lógica. Em uma primeira impressão, a noção de rede constitui uma lógica descentrada e é, atualmente, retroalimentada pelo registro da 
virtualidade. Haja vista o que temos assistido no campo da política no mundo e, em particular, no Brasil, onde, recentemente, por meio dos movimentos em rede na internet, facebook, assistimos o povo nas ruas, gritando por melhorias no país. As "vozes da rua", como foram chamadas, organizaram-se na rede virtual e tomaram as ruas das cidades. As vozes-potência da virtualidade se atualizaram nas ruas. Um movimento marcado pela lógica da horizontalidade, no qual seus representantes se organizam em torno de reivindicações, protestos e denúncias. E isso se deve, essencialmente, ao fato de que os neossujeitos estão inscritos na/pela vivência da virtualidade, filhos da ciência e da tecnologia. Porém, e paradoxalmente, se por um lado esses neossujeitos podem tornar-se errantes na metonímia discursiva da rede, aprisionados pela imagem, por outro lado, o estado de mal-estar gerado pela fixidez nessa posição pode favorecer a enunciação de vozes dirigidas para determinados fins, como se observou nas "vozes da rua" e nas vozes das agentes comunitárias de saúde que, despertando do "fingimento" de que nada acontecia com a menina abusada sexualmente, foram à rua convocar a avó a ocupar uma função de interdição. Apostar na dimensão paradoxal da experiência da virtualidade também ajuda a refletir sobre as respostas dos sujeitos diante dos seus mal-estares e nos possíveis efeitos do desmentido sobre eles mesmos.

Partindo dessas considerações, vejamos como podemos, então, discutir os efeitos do desmentido e suas vicissitudes. Antes, porém, lembramos que Lebrun (2008) afirma que

o efeito da renegação - ou do desmentido - , como o da foraclusão, consiste numa abolição simbólica. Mas é apenas de uma das duas vertentes da clivagem. E na outra vertente, não há precisamente abolição. É portanto bem na coexistência simultânea desses dois aspectos que reside a especificidade dos efeitos do desmentido. (p. 262)

Para o autor, os efeitos do desmentido são considerados a vertente da abolição simbólica e a vertente em que não há abolição simbólica. Essa contribuição do autor ajuda a ratificar o caráter paradoxal que subjaz na experiência dos neossujeitos: uma em que nega a função paterna, prescindindo dela; outra em que, atolado na virtualidade, movimenta-se rumo ao encontro do outro, em busca de enunciar possibilidades.

$\mathrm{O}$ desmentido como mecanismo de defesa do perverso e como mecanismo de negação de todos tem seus efeitos no Outro e no social de forma mais ampla. Parece-me que o desmentido provocaria dois efeitos: o primeiro quando UM perverso assujeita o outro a seu gozo e o destitui do lugar de sujeito de desejo. $\mathrm{O}$ desmentido do perverso, nesse caso, tem força devastadora sobre a subjetividade do outro. É capaz de aprisioná-lo e violentá-lo. Quando discutimos a violência sofrida pela menina, constatamos que, de alguma forma, todos sabiam do fato, porém, pareciam não se dar conta de sua gravidade. Isso sugere certa generalização do desmentido em nome do imperativo Gozar. Nessa situação, parece que 
o que prevalece é uma sociedade marcada essencialmente pela perversão. Os interlocutores compartilham com o outro por meio do laço perverso, do desmentido que marca a origem psíquica de cada um. Diferentes autores têm denunciado o caráter mortífero e de abolição simbólica do desmentido quando afirmam que o Outro está atolado no imaginário e que há uma falência simbólica, como lembra Lebrun (2008) ao refletir sobre a perversão comum e um coletivo entodado. Ainda sob essa perspectiva, o que sobressai são passagens ao ato e uma dificuldade de produzir demandas simbólicas. Aqui, o que se observa é o laço com o desmentido original, porém, não se pode afirmar que todos são perversos, o que invariavelmente se encontra é um outro perverso ocupando um lugar de tudo saber e fazer. Tal lugar pode ser ocupado pelos discursos da ciência, da tecnologia, do consumo, por exemplo. Em certo sentido, todos gozam com o desmentido, pois se faculta a todos a possibilidade de gozar de diferentes formas: vendo, ouvindo, sabendo, agindo etc.

$\mathrm{Na}$ segunda possibilidade, o horror gerado pelo desmentido dá passagem ao mal-estar, ou seja, o mal-estar do coletivo é capaz de interditar o gozo perverso de UM que é da ordem do horror. A constatação de que há um "fingimento" operando, como denunciado pela ACS, leva todos a reposicionar o lugar da lei, interditando o gozo de um que havia se transformado em gozo de todos. A cada vez que se instala o mal-estar e denuncia-se o desmentido de cada um, e de todos, o trabalho do simbólico é reinstalado e isso produz um efeito no Outro, no social, na comunidade. Parece, então, que o Outro é sempre permeável à operação do desmentido. Há sempre uma tensão entre esses dois endereçamentos do desmentido. $\mathrm{O}$ fato de haver essa tensão não justifica a hipótese de que há uma fragilidade do simbólico. É uma tensão complexa que nunca está acabada, assim como não está acabado o processo civilizatório. E, sobre isso, podemos lembrar da contribuição freudiana sobre o mal-estar na civilização. Trata-se de um trabalho interminável, onde o mecanismo do desmentido parece se realçar nesse processo. Afirma-se que o simbólico é permeável às operações do desmentido, tem-se favorecido na contemporaneidade uma sensação de fim dos tempos, no qual o gozo é o imperativo na cultura. Entretanto, essa mesma permeabilidade tem favorecido, também, uma série de eventos significativos, como os que foram descritos nos movimentos e nas organizações em rede. Nas redes virtuais que se materializam e se atualizam nos espaços urbanos, na cidade, na pólis. E, por fim, no trabalho em rede de cuidados desenvolvidos na micropolítica do cotidiano na saúde pública, como no caso relatado da menina de 12 anos que, voltando à escola e a brincar na rua, foi possível voltar a sonhar.

Agradecimentos: Agradecemos, principalmente, aos agentes comunitários de saúde da Unidade de Saúde da Família Sítio Wanderley, em Recife (PE), por se disponibilizar a participar e apostar no trabalho que desenvolvemos nessa unidade de saúde, e aos demais profissionais que aceitaram e concordaram com nosso 


\section{ARTIGOS}

projeto. Aos estudantes de Terapia Ocupacional da UFPE que participaram ativamente dos grupos reflexivos, inclusive relatando-os. Em especial a Tatiany Lisiére Brandão Küzler Lima, Juliana Figueredo Sobel, Bárbara Katiene Magno e Plínia Manuella de Santana Maciel.

\section{Referências}

Castells, M. (1999). A era da informação: economia, sociedade e cultura. A sociedade em rede (vol. 1, 5. ed.). São Paulo: Paz e Terra.

Lebrun, J. (2004). Um mundo sem limite: ensaio para uma clínica psicanalítica do social. Rio de Janeiro: Companhia de Freud.

Lebrun, J. (2008). A perversão comum. Rio de Janeiro: Campo Matêmico.

Mittman, S. (2011). Alguns apontamentos sobre militância digital. In E. Grigoletto,, F. S. de Nardi, \& C. R. Schons (Orgs.), Discurso em rede: práticas de (re)produção, movimentos de resistência e constituição de subjetividades no ciberespaço. Recife: Ed. UFPE.

Queiroz, E. F. (2004). A clínica da perversão. São Paulo: Escuta.

\section{Resumos}

(Perversion in the territory: the effects of denial)

This paper discusses the effects of pervert's denial (Verleugnung) of the other, the collectivity and highlights its possible directions. The related research was carried out at a family health unit in Recife, Pernambuco, Brazil, and the participants were female community health workers in discussion groups. We discussed a clinical fragment in which a child had been abused by a perverse individual. There was a clear need for intervention to stop the pervert's jouissance and free the child.

Key words: Perversion, primary health care, psychoanalysis, mental health

(La perversion dans le territoire: les effets du déni)

Cet article discute les effets du déni (Verleugnung) du pervers sur l'autre, la collectivité, en soulignant ses possibles adressages. Il s'agit d'une recherche-action menée dans une unité de Santé de la Famille à Recife, Pernambuco, Brésil. Les participants étaient composés d'agents de santé communautaires distribués dans des groupes de discussion. Un fragment clinique selon lequel un enfant était abusé par un pervers a été discuté. La nécessité d'une intervention a été soulignée pour entamer la jouissance du pervers et libérer l'enfant.

Mots clés: Perversion, soins de santé primaires, psychanalyse, santé mentale 
(La perversión en el territorio: los efectos del desmentido)

Este artículo relata una investigación-acción llevada a cabo en una unidad de Salud de la Familia en Recife, Pernambuco, Brasil. Los participantes fueron agentes comunitarios de salud en grupos de discusión. Se discutió un fragmento clínico en el que un niño era abusado por un pervertido. Se destacó la necesidad de una intervención para impedir el goce del pervertido y libertar al niño. A partir de eso, se discuten los efectos del desmentido (Verleugnung) del pervertido sobre el otro, la colectividad, destacando sus posibles direccionamientos.

Palabras clave: Perversión, atención primaria de salud, psicoanálisis, salud mental

(Die Perversion im Handlungsfeld: Auswirkungen der Verleugnung)

In diesem Beitrag werden die Auswirkungen der Verleugnung des Perversen gegenüber des Anderen, des Kollektivs, besprochen, wobei die möglichen Ziele hervorgehoben werden. Es handelt sich um eine empirische Untersuchung in einer Behandlungseinheit der Einrichtung Saúde da Familia (Gesundheit der Familie) in Recife, Pernambuco. Die Teilnehmer waren Gesundheitshelfer der Gemeinden in Reflexionsgruppen. Die Problemstellung bestand aus einem klinischen Fragment, in dem ein Kind von einer perversen Person vergewaltigt wurde. Dabei wurde ein besonderes Augenmerk auf die Notwendigkeit einer Intervention gelegt, um dem Genuss des Perversen Einhalt zu gebieten und das Kind zu befreien.

Schlüsselwörter: Perversion, primäre Beachtung der Gesundheit, Psychoanalyse, geistige Gesundheit

Citação/Citation: Lima Filho, I. de A.; Facundes, V.L.D. (2014, setembro). A perversão no território: os efeitos do desmentido. Revista Latinoamericana de Psicopatologia Fundamental, 17(3-Supp1.), 686-695.

Editor do artigo/Editor: Prof. Dr. Manoel Tosta Berlinck

Recebido/Received: 15.3.2014/ 3.15.2014 Aceito/Accepted: 15.4.2014 / 4.15.2014

Copyright: (C) 2009 Associação Universitária de Pesquisa em Psicopatologia Fundamental/ University Association for Research in Fundamental Psychopathology. Este é um artigo de livre acesso, que permite uso irrestrito, distribuição e reprodução em qualquer meio, desde que o autor e a fonte sejam citados / This is an open-access article, which permits unrestricted use, distribution, and reproduction in any medium, provided the original author and source are credited. 


\section{ARTIGOS}

Financiamento/Funding: Os autores declaram não ter sido financiados ou apoiados / The authors have no support or funding to report.

Conflito de interesses/Conflict of interest: Os autores declaram que não há conflito de interesses / The authors have no conflict of interest to declare.

\section{Ivo de Andrade Lima Filho}

Prof. Adjunto do Departamento de Terapia Ocupacional da Universidade Federal de Pernambuco - UFPE (Recife, PE, Br); Doutor em Linguística pela mesma Universidade; Psicanalista (CPP) e membro do Laboratório de Pesquisa em Psicopatologia Fundamental e Psicanálise da Universidade Católica de Pernambuco - Unicap (Recife, PE, Br).

Rua das Graças, 326, bloco A, apto. 901 - Graças

52011-200 Recife, PE, Br

e-mail: ivoalf@bol.com.br

\section{Vera Lúcia Dutra Facundes}

Profa. Adjunta do Departamento de Terapia Ocupacional da Universidade Federal de Pernambuco - UFPE (Recife, PE, Br); Doutora em Neuropsiquiatria e Ciências do Comportamento pela mesma Universidade.

Rua Visconde de Itaparica, 142, bloco A, apto. 1504 - Torre

50710-090 Recife, PE, Br

e-mail: verafacundes@yahoo.com.br 